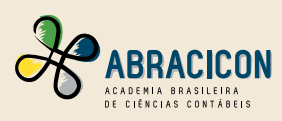

DOl: http://dx.doi.org/10.17524/repec.v10i1.1333

\title{
Uso da Análise Hierárquica (AHP) para Identificação da Preferência de Peritos- Contadores Quanto ao Método de Avaliação de Sociedades em Perícias Contábeis
}

\section{Resumo}

Este artigo teve como objetivo evidenciar quais são as preferências dos peritos-contadores quanto à escolha do método de avaliação de sociedades em perícias contábeis, como também os principais critérios, quantificados com base em método multicriterial, denominado Método de Análise Hierárquica (AHP). Abordou-se no referencial teórico a relação entre a perícia contábil e a avaliação de sociedades, na qual o procedimento pericial é denominado como apuração de haveres. Foram apresentados os principais métodos de avaliação de empresas e o Balanço de Determinação, que é um procedimento determinado pelo judiciário brasileiro que evidencia os ativos a valor de mercado, os passivos a valor presente e o goodwill. O uso do AHP mostrou-se apto para a pesquisa, evidenciando a preferência dos peritos-contadores pelo Balanço de Determinação com Fluxo de Caixa Descontado (ABDFC), com 62,66\%. Dentre os critérios estabelecidos para a escolha do método de avaliação de sociedades, a continuidade foi o que obteve maior percentual com $46,13 \%$.

Palavras-chave: Avaliação de sociedades. Perícia contábil. Apuração de haveres. AHP.

\section{Claudio Roberto Caríssimo \\ Mestre em Ciências Contábeis pela Universidade Federal de Minas Gerais (UFMG) e Professor e pesquisador na Universidade Federal de Alfenas - Campus Varginha. Contato: Avenida Celina Ferreira 0ttoni, 4000. Padre Vitor. Varginha-MG, CEP: 37048-395. E-mail: crcarissimo@gmail.com}

\section{Marcia Athayde Moreira} Doutora em Ciências Contábeis pela Universidade São Paulo (USP) e Professora do Programa em Administração da Universidade da Amazônia. Contato: Avenida Alcindo Cacela, 287, bloco E, $4^{\circ}$ andar. Umarizal. Belém-PA, CEP: 66060-902. E-mail: athayde.marcia@gmail.com

\section{Martinho Maurício \\ Gomes de Ornelas}

Doutor em Ciências Contábeis pela Universidade São Paulo (USP) e Sócio da Ornelas \& Associados Perícia Contábil e Arbitragem S/S Ltda. Contato: Av. Paulista, $326,14^{\circ}$ andar, cj. 145. Bela Vista. São Paulo-SP, CEP: 01310-902.

E-mail:m.ornelas@contadoresforenses.net.br

Jersone Tasso Moreira Silva

Doutor em Economia Aplicada pela Universidade Federal de Viçosa e Professor e pesquisador da Universidade Fumec. Contato: Av. Afonso Pena, 3880, $1^{\circ}$ Andar. Cruzeiro. Belo Horizonte-MG, CEP: 30310-009.

E-mail: tasso@fumec.br 


\section{Introdução}

A perícia contábil, cumprindo os objetivos da contabilidade, também gera informação útil para a tomada de decisão, sendo ainda instrumento de prova, evidenciação e verificação da veracidade dos fatos. Dentre os procedimentos periciais está a apuração de haveres, que busca mensurar o valor justo da sociedade, via de regra, em ações que versam sobre dissolução parcial de sociedades ou até mesmo em inventários. Para a mensuração do valor justo da sociedade, o perito-contador poderá utilizar-se das metodologias emanadas do arcabouço da teoria de finanças e da teoria da avaliação patrimonial e do lucro, devendo os procedimentos periciais ser suportados pela neutralidade, confiabilidade e verificabilidade. Conforme entendimento dos teóricos, não existe algum método a ser empregado para todos os tipos de empresas que seja absoluto e independente dos contextos nos quais esteja inserida a sociedade. Dessa forma, cabe ao perito-contador utilizar determinados métodos que dependem das características, previsões e atributos dos ativos, assim como da condição de continuidade do empreendimento. O perito-contador deve estar ciente das ferramentas que poderá utilizar para cumprir sua tarefa, tendo em conta as condições e restrições inerentes aos métodos avaliatórios.

O arcabouço da Teoria de Finanças e a Teoria da Avaliação Patrimonial e do Lucro oferecem toda a base para a construção dos modelos de avaliação de sociedades, formados por abordagens que avaliam o empreendimento com base em perspectivas futuras de caixa, capacidade de gerar lucros acima do normal, comparação com avaliações de empresas semelhantes ou multiplicadores de faturamento, e avaliação dos ativos pelo valor contábil ou de mercado em função da descontinuidade do negócio e, a contraponto, a continuidade do empreendimento como determinante para a escolha do modelo de avaliação e apuração do goodwill (Iudícibus, 2000; Damodaram, 2005; Assaf Neto, 2006).

Nesse conjunto de modelos e aplicações empíricas por meio de métodos de avaliação de sociedades, emergem outras questões que merecem atenção, tais como os critérios de escolha desses métodos de avaliação e os procedimentos complementares que buscam oferecer validade e confiabilidade à avaliação e à conclusão do laudo. Tais aspectos demandam um processo de escolha, de decisão sobre o que empregar, quando e como.

É este contexto que se destaca o Método de Análise Hierárquica (em inglês, AHP). Este método auxilia em processos de tomada de decisão, que envolve a análise de múltiplos critérios que impactam a avaliação das variáveis que influenciam o problema e a alternativa resultante da escolha. Conforme seu idealizador, Thomaz Saaty, é usado para responder às questões sobre o tipo de preferências do tomador da decisão e as alternativas disponíveis ou almejadas, como também para responder às questões sobre o que é mais importante no nível dos critérios e o que é mais provável no nível das alternativas (Saaty, 1997).

A utilização do método AHP pode evidenciar quais são as prioridades dos peritos-contadores para a escolha dos métodos de avaliação de sociedades, como também qual método apresenta uma preferência em relação aos demais. Assim se estabelece a questão que norteará essa pesquisa: É possível identificar, a partir da aplicação do método AHP, uma preferência dos peritos-contadores na escolha do método e abordagens na avaliação de sociedades em perícias de apuração de haveres?

\section{Perícia Contábil e a Avaliação de Sociedades em Processos de Apuração de Haveres}

A perícia judicial, conforme o Art. 420 do Código de Processo Civil, consiste em um exame, vistoria ou avaliação, podendo ser entendida também como um instrumento de prova, constatação e verificação da veracidade. $O$ trabalho pericial se concretiza por meio de uma peça, ou relatório, fundamentada científica e tecnicamente, apresentando uma constatação conclusiva sobre a verdade do fato, resultando, inclusive, na própria prova pericial contábil (Alberto, 2000; Ornelas, 2000b)

O Art. 145 do CPC preceitua que quando "a prova do fato depender de conhecimento técnico ou científico o juiz será assistido por perito", segundo o disposto no Art. 421 (Brasil, 1973, p. 267). Este procedimento 
pericial contábil se faz presente não somente no judiciário brasileiro, como também se evidenciam publicações internacionais focadas neste tema, conforme destacam Laro e Pratt (2005).

Pires (2006, p. 60) destaca que a prova pericial é constituída mediante a aplicação de procedimentos técnicos, com o "objetivo de estabelecer o nexo causal do dano com o objeto de pedir da ação". Para Peleias, Nogueira, Parisi e Ornelas (2009), a perícia contábil judicial representa uma atividade profissional de prestação de um serviço técnico especializado, tendo como usuários da informação gerada os juízes e as partes do processo.

Paulo, Cunha, Alencar \& Martins (2006) ressaltam que, em processos de apuração de haveres, para apurar o valor da sociedade, o perito-contador deverá utilizar procedimentos respaldados em literatura técnica.

Dessa forma, a construção do laudo pericial tem por objetivo elucidar aspectos ou situações que requerem conhecimento técnico/científico, devendo ainda apresentar sua validade e confialibilidade, amparado nos aspectos qualitativos da informação contábil, tais como, representação fiel do valor da empresa, neutralidade e verificabilidade e fundamentação teórica do trabalho realizado, conforme defendido por Tibúrcio Silva (2008).

Nota-se que o trabalho pericial, quando realizado com o objetivo de apurar haveres, deve não só estar revestido dessa fundamentação teórica e consistência técnica, posto que, conforme Ornelas (2003, p. 102), "há que se justificar, categoricamente, como obteve o valor fixado".

\section{O Valor Justo e a Avaliação de Sociedades em Apuração de Haveres}

A mensuração do valor justo, conforme respaldo das IFRS, deve advir de transações não forçadas, sem pressões impostas pelo mercado (Shanklin, Hunter \& Ehlen, 2011). Tendo-se como direcionador o Comitê de Procedimentos Contábeis, por meio do CPC 46, que trata sobre a mensuração do valor justo, amplia-se a compreensão do processo avaliatório, percebendo que o valor justo pode advir de estimações estabelecidas de forma imparcial, contudo utilizando-se das mesmas premissas que os participantes do mercado poderiam utilizar ao precificar o ativo objeto da avaliação.

Reforça-se assim o caráter imparcial e preciso que a perícia em apuração de haveres deve estar calcada, com apoio na qualidade da informação gerada, cujo objetivo é esclarecer às partes e ao magistrado. Esta informação deve estar embasada em procedimentos respaldados pela teoria contábil e/ou de finanças. Dessa forma, entende-se que o sentido da mensuração pelo valor justo adéqua-se perfeitamente aos objetivos e procedimentos da perícia judicial em apuração de haveres.

Além da imparcialidade inerente e condicional ao trabalho pericial, não é raro o perito- contador ter de minimizar ou eliminar quaisquer condições de assimetria informacional. Portanto, nesse processo de avaliação se consubstancializa toda a condição e justificativa da busca do valor justo em todo seu aspecto conceitual e empírico.

\section{Métodos de Avaliação}

Para Damodaram (1997), não existe um melhor método para avaliar empresas. A escolha do método a ser utilizado dependerá de cenário específico e de uma variedade de características do ativo ou da empresa avaliada. Neste mesmo raciocínio, Martins et al. (2001) acrescentam que não existe uma fórmula absoluta.

Com o viés das finanças, Martelanc, Pasin e Pereira (2010) destacam que os métodos de avaliação de empresas mais utilizados são: contábil/patrimonial; fluxo de caixa descontado, múltiplos ou avaliação relativa; e de EVA/MVA (Economic Value Added e Market Value Added), e que os bancos de investimento e as empresas de consultoria têm maior preferência pelo método do Fluxo de Caixa Descontado.

Para Fernández (2007), os métodos de avaliação são divididos em seis principais grupos, destacando que no campo das finanças corporativas, o entendimento dos mecanismos dos processos de avaliação de empresas é indispensável. O Quadro 1 abaixo exemplifica alguns desses métodos por grupo de avaliação. 
Quadro 1

Grupos de métodos de avaliação de empresas

\begin{tabular}{|c|c|c|c|c|c|}
\hline $\begin{array}{c}\text { Balanço } \\
\text { Patrimonial }\end{array}$ & $\begin{array}{l}\text { Resultado } \\
\text { Econômico }\end{array}$ & Misto (Goodwill) & $\begin{array}{c}\text { Fluxo de Caixa } \\
\text { Descontado }\end{array}$ & $\begin{array}{l}\text { Criação de } \\
\text { Valor }\end{array}$ & Opções \\
\hline $\begin{array}{l}\text { - Modelo do valor } \\
\text { contábil } \\
\text { - Modelo do } \\
\text { valor contábil } \\
\text { ajustado } \\
\text { - Modelo do valor } \\
\text { de liquidação } \\
\text { - Modelo do valor } \\
\text { substancial }\end{array}$ & $\begin{array}{l}\text { - Modelo do } \\
\text { valor dos } \\
\text { lucros } \\
\text { - Modelo do } \\
\text { valor dos } \\
\text { dividendos } \\
\text { - Modelo dos } \\
\text { múltiplos de } \\
\text { vendas }\end{array}$ & $\begin{array}{l}\text { Modelos: } \\
\text { - Clássico } \\
\text { - Simplificado da União } \\
\text { Européia } \\
\text { - dos peritos contábeis } \\
\text { europeus } \\
\text { - Método indireto } \\
\text { - Método de compra de } \\
\text { lucros anuais } \\
\text { - Modelo da taxa de risco } \\
\text { relativo e de risco livre }\end{array}$ & $\begin{array}{l}\text { - } \text { Fluxo de Caixa } \\
\text { Livre } \\
\text { - Fluxo de Caixa } \\
\text { Patrimonial } \\
\text { - Fluxo de Caixa } \\
\text { do capital } \\
\text { - Modelo de } \\
\text { dividendos } \\
\text { - Valor Presente } \\
\text { Ajustado (APV) }\end{array}$ & $\begin{array}{l}\text { - Economic Value } \\
\text { Added (EVA) } \\
\text { - Fluxo de } \\
\text { Caixa do } \\
\text { Retorno sobre } \\
\text { Investimentos } \\
\text { (CFROI) }\end{array}$ & $\begin{array}{l}\text { - Black e Scholes } \\
\text { - Opção de } \\
\text { Investimento } \\
\text { - Expansão de } \\
\text { projeto } \\
\text { - Adiamento de } \\
\text { Investimento }\end{array}$ \\
\hline
\end{tabular}

Fonte: Fernández (2007, p. 4)

Hitchner (2003) e Laro e Pratt (2005) destacam que as abordagens para se determinar o valor de uma empresa podem basear-se no valor justo de mercado (comparações de preços de mercado), no valor do investimento (conforme atributos definidos pelo investidor), no valor intrínseco (baseando em análise fundamentalista) ou no valor contábil (apurado com base nas demonstrações financeiras).

Em perícias judiciais de apuração de haveres, conforme Tibúrcio Silva (2008) existem diversos métodos que podem ser utilizados: Nova York, Hatfield, Ornelas, Moschini e Scotti, Pellegrino, Método de Delaware e múltiplo de venda.

\section{Balanço de Determinação}

O Balanço de Determinação, apesar de não ser um método de avaliação de sociedades, propriamente dito, tem a função de evidenciar o valor de mercado do patrimônio líquido da sociedade. Mantém relação com o balanço especial, constante no Art. 1.031 do Código Civil Brasileiro, Lei n. ${ }^{\circ}$ 10.406/2002, todavia, não deve ser confundido com este, posto que o balanço especial evidencia a situação patrimonial da entidade na data do evento, enquanto o Balanço de Determinação evidencia os ativos a valor de mercado, os passivos a valor presente e o goodwill, quando a sociedade apresenta atributos para tê-lo.

De acordo com Ornelas (2003, p. 83), o Balanço de Determinação é "elaborado para a data do evento, na qual os elementos patrimoniais são avaliados e consignados a valores de mercado. É utilizado para determinar o montante dos haveres do sócio retirante ou falecido".

Ornelas (2000a); Perez e Famá (2004) apontam a Súmula 265 do Supremo Tribunal Federal (STF), na qual consta: "Na apuração de haveres, não prevalece o balanço não aprovado pelo sócio falecido ou que se retirou". Assim, conforme Ornelas (2000a) inexistindo o balanço para a data do evento ou, ainda, existindo, mas sem a aprovação do sócio retirante, nos processos de apuração de haveres, deverá ser levantado um Balanço de Determinação.

Infere-se dessa revisão que, apesar de não haver lei específica instituindo ou obrigando a utilização do Balanço de Determinação, nem norma para este fim expedida pelo CFC, Ornelas (2000a); Hoog (2010), Santos (2011) e De Oliveira (2011) consideram a sua utilização como procedimento contábil que visa suprir informações mais precisas e confiáveis quando da resolução societária, cumprindo de forma eficaz o entendimento emanado do Poder Judiciário via acórdãos exarados pelos tribunais estaduais e pelo Superior Tribunal de Justiça. 


\section{O Método AHP - Analytic Hierarchy Process}

Segundo Saaty (1997), nos processos de tomada de decisão, havendo uma estrutura adequada capaz de oferecer condições de analisar todo o processo da decisão, é possível prever a melhor alternativa apesar das condições do presente e do futuro, resultando em uma decisão com melhor fundamento.

Para otimizar o processo de tomada de decisão, Saaty desenvolveu o método Analytic Hierarchy Process (AHP), que tem sua essência alicerçada na comparação e alocação dos pares, procedimento já utilizado pelos psicólogos, denominados por eles de comparações pareadas (Ishizaka \& Labib, 2011), Saaty (1997) descreve que o método AHP pode ser usado para responder a questões de preferência, em termos de alternativas, destinado a ser descritivo, não uma teoria normativa.Destaca o autor que o método é usado para responder a perguntas sobre o que é mais importante com base nos critérios estabelecidos, e/ou o que é mais provável em termos de alternativas.

Conforme Kroenke e Hein (2011), este método permite a criação de uma estrutura hierárquica por meio de prioridades, podendo ser utilizado como apoio à tomada de decisão, como por exemplo, na definição de uma classificação de empresas de determinado setor em função de índices estruturados hierarquicamente. De acordo com o próprio Saaty, o AHP pode ser utilizado para modelar e estruturar problemas econômicos, sociais e gerenciais (Saaty, 1991).

O método AHP é um instrumento de apoio à tomada de decisão que busca determinar de forma clara e por meio da síntese dos valores e das características de cada alternativa aquelas que serão priorizadas ou classificadas, apurando-se, por fim, uma medida global que evidenciará a melhor alternativa derivada dos critérios e dos julgamentos realizados. Essa estruturação de níveis hierárquicos facilita a compreensão e avaliação desses critérios, para a escolha da melhor alternativa (Gomes, Araya \& Carignano, 2004).

Lyra (2008, p. 51) destaca de forma sintética que o processo de utilização do AHP é formado basicamente por cinco etapas:

a) definir o problema e a estrutura hierárquica;

b) construir matrizes de prioridade;

c) obter as matrizes de prioridades relativas;

d) checar as consistências das matrizes;

e) decidir as prioridades.

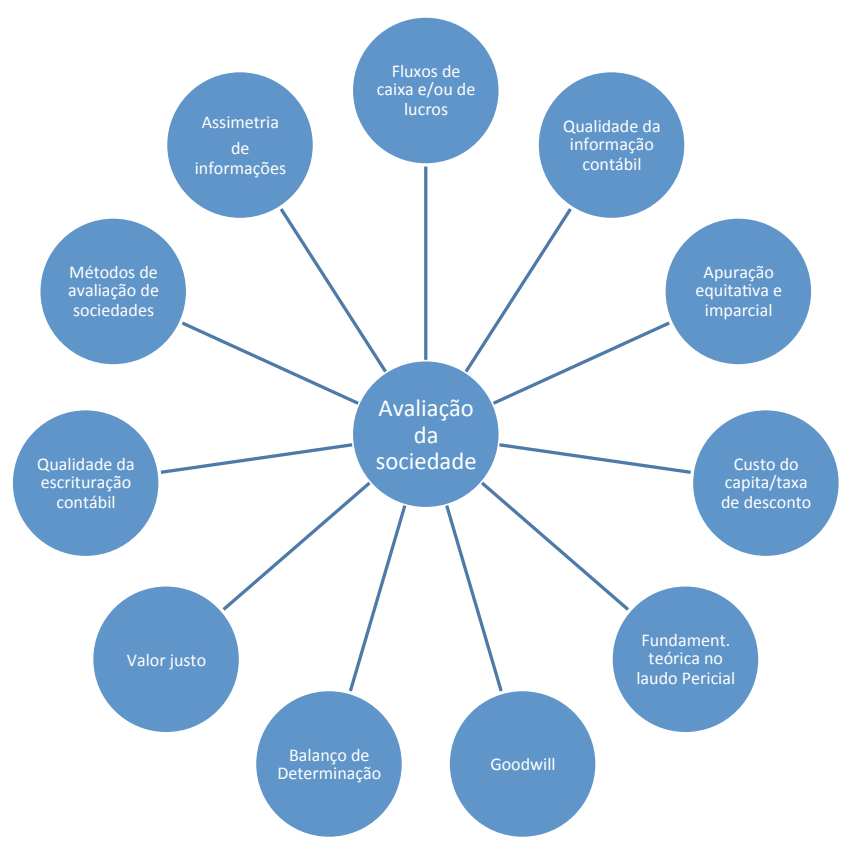

Figura 2. Decisões e procedimentos na avaliação da sociedade em perícias de apuração de haveres

Fonte: elaborado pelos autores. 
A Figura 2 exemplifica a variedade de abordagens, procedimentos e, por que não dizer, decisões inerentes ao processo de avaliação de sociedades que deverão ser considerados quando do trabalho de apuração de haveres, tais como: fundamentação teórica no laudo, qualidade da escrituração contábil e a busca pelo valor justo.

\subsection{O Problema e a Estrutura Hierárquica}

No processo de tomada de decisão, deverá ser feita a estruturação do problema, sendo esta uma das vantagens do método AHP, pois permite a construção de uma estrutura hierárquica para os critérios, fornecendo aos usuários um foco mais objetivo e evidenciando critérios específicos e subcritérios para posterior atribuição dos pesos (Ishizaka \& Labib, 2011). Lyra (2008) ressalta que a etapa de estruturação do problema e de elaboração da hierarquia é de total importância, pois após a atribuição de pesos, será possível realizar o processo de comparação par a par dos critérios e, posteriormente, das alternativas.

\subsection{Comparações dos Pares e a Matriz de Escala}

Na aplicação do Método de Análise Hierárquica, as comparações dos pares são fundamentais para a sua utilização (Saaty, 1987), devendo ser estabelecidos os principais critérios de julgamentos desses pares e a importância relativa nessas comparações, sendo que os julgamentos serão representados por números de uma escala fundamental e ordenados por uma matriz de ordem $n$. Conforme Saaty, a formação da matriz de comparação é dada por:

$$
\begin{array}{lll}
\mathrm{a}_{i j}>0 & \text { para } i=1,2, \ldots, \mathrm{n} & j=1,2, \ldots \mathrm{n} \\
\mathrm{a}_{j i}=1 / \mathrm{a}_{i j} & \text { para } i=1,2, \ldots, \mathrm{n} & j=1,2, \ldots, \mathrm{n}
\end{array}
$$

Os elementos acima da diagonal principal, representados por $\mathrm{a}_{\mathrm{ij}}$, são formados pelos julgamentos paritários com a escala de 1 a 9 e os elementos abaixo da diagonal principal são representados por $\mathrm{a}_{\mathrm{ji}}$ apurado por $1 / \mathrm{a}_{\mathrm{ij}}$, Os julgamentos, contudo, devem ser quantificados aos pares de critérios, $\boldsymbol{I}_{i} \mathrm{e} \boldsymbol{I}_{j}$, devendo ser representados por uma matriz $\boldsymbol{n} \mathbf{x} \boldsymbol{n}$, ou seja, uma matriz quadrática, posto que a comparação será sempre paritária (um a um) (Lyra, 2008). Essas matrizes são positivas e recíprocas (Saaty, 1987). Ou seja, os elementos abaixo da diagonal principal são função recíproca dos elementos acima desta diagonal. Dessa forma, sendo $\mathrm{a}_{i j}>0$, $\mathrm{a}_{j i}$ será $=1 / \mathrm{a}_{i j}$.

$$
A=\left[\begin{array}{ccccc}
1 & a_{12} & a_{13} & \ldots & a_{1 j} \\
1 / a_{12} & 1 & a_{23} & \ldots & a_{2 j} \\
1 / a_{13} & 1 / a_{23} & 1 & \ldots & a_{3 j} \\
\ldots & \ldots & \ldots & 1 & \ldots \\
1 / a_{1 j} & 1 / a_{2 j} & 1 / a_{3 j} & \ldots & 1
\end{array}\right]
$$

Conforme Lyra (2008, p. 55), nestas matrizes de julgamento, em que os elementos $\mathbf{a}_{\mathrm{ij}}$ representam um número que indica a importância de $\boldsymbol{I}_{i}$ quando comparado $\operatorname{com} \boldsymbol{I}_{\boldsymbol{j}}$, as seguintes condições devem ser atendidas:

Regra 1: Se $\mathbf{a}_{\mathrm{ij}}=\alpha$, então $\mathbf{a}_{\mathrm{ji}}=\mathbf{1} / \alpha, \alpha \neq \mathbf{0}$. para todo $\mathbf{i}$.

Regra 2: Se $\boldsymbol{I}_{i}$ é julgado como de igual importância a $\boldsymbol{I}$, então $\mathbf{a}_{\mathrm{ij}}=\mathbf{1}, \mathbf{a}_{\mathrm{ji}}=\mathbf{1}$. E, em particular, $\mathbf{a}_{\mathrm{ii}}=\mathbf{1}$ 
A construção das matrizes de julgamentos são formadas em função de escalas de intensidades de importância, que deverão ser determinadas para cada critério ou subcritério. Conforme sugestão de Saaty (1991), as escalas de intensidade são determinadas conforme o Quadro 2 abaixo:

Quadro 2

Escala de intensidade de importância

\begin{tabular}{cll}
$\begin{array}{c}\text { Intensidade de } \\
\text { importância }\end{array}$ & Definição & Explanação \\
\hline 1 & Mesma importância & As duas atividades contribuem igualmente para o objetivo \\
\hline 3 & $\begin{array}{l}\text { Importância moderada de um sobre o } \\
\text { outro }\end{array}$ & $\begin{array}{l}\text { A experiência e o julgamento favorecem levemente uma } \\
\text { atividade em relação a outra }\end{array}$ \\
\hline 5 & Importância forte ou essencial & $\begin{array}{l}\text { A experiência e o julgamento favorecem fortemente uma } \\
\text { atividade em relação a outra }\end{array}$ \\
\hline 9 & Importância muito forte & $\begin{array}{l}\text { Uma atividade é muito fortemente favorecida e seu } \\
\text { domínio é demonstrado na prática }\end{array}$ \\
\hline $2,4,6,8$ & $\begin{array}{l}\text { Valores intermediários entre dois } \\
\text { julgamentos adjacentes }\end{array}$ & $\begin{array}{l}\text { A evidencia favorece uma atividade sobre a outra, sendo } \\
\text { da mais alta ordem de afirmação }\end{array}$ \\
\hline
\end{tabular}

Fonte: adaptado de Saaty $(1987,1991)$.

\subsection{Normalização e Consistência das Prioridades}

Seguindo a sequência estabelecida por Saaty (1991), o próximo passo consiste na normalização da matriz de prioridades, em que se calculam os pesos relativos de cada elemento da matriz em função do somatório da coluna à qual pertence. Conforme Lyra (2008), neste processo de normalização da matriz, calcula-se o autovetor, que, após a normalização, se tornará o vetor de prioridades.

A matriz resultante do processo de normalização será assim definida (Santos, 2008):

$$
A^{\prime}=\left[a_{i j}^{\prime}\right] \text { onde } a_{i j}^{\prime}=a_{i j} / \sum_{k=1}^{n} a_{i k} \text { para } 1 \leq i \leq n \text {, e } 1 \leq j \leq n
$$

O passo seguinte é obter as Prioridades Médias Locais, conforme Costa (2002), ou o cálculo do peso relativo de cada alternativa (Lyra, 2008). Este peso relativo será calculado pela média aritmética de cada linha. Após o cálculo dos vetores de Prioridades Médias Locais (PML), será realizada a apuração da Prioridade Global (PG), pois o que se quer é identificar um vetor "que armazene a prioridade associada a cada alternativa em relação ao foco principal ou objetivo global" (Costa, 2002, p. 61). Para o cálculo da PG, devem-se combinar as PML's, no vetor de Prioridades Global (PG). Santos (2008) esclarece que o resultado será a apuração de um único valor de peso (C) para cada escolha da decisão, representado pela seguinte notação matemática, em que o peso composto, $C$, é dado por:

$$
C=\left[c_{d}\right] \text { para } 1 \leq d \leq n \text { onde } c_{d}=\sum_{t=1}^{n t} W_{t} * \prod_{l=1}^{n 1-1} W_{l}
$$


Sendo $\mathbf{A}=\left(\mathbf{a}_{\mathrm{ij}}\right)$, uma matriz $n \mathrm{x} n$ de elementos positivos, $\boldsymbol{a}_{i j}=\boldsymbol{a}_{j i}^{-1}$, " $\mathrm{A}$ " será consistente se, e somente se, $\lambda_{\max } \geq \mathrm{n}$ (Saaty, 1991, p. 272). Ou seja, os valores de aij, em razão de terem sido obtidos por meio de julgamentos subjetivos, podem não estar embasados em medidas exatas. Para calcular a consistência das matrizes, Saaty (1987) considerou a seguinte equação:

$$
I C=\frac{\left|\lambda_{M A X}-N\right|}{N-1}
$$

Em que,

$I C=$ Índice de Consistência;

$N$ = Dimensão da Matriz;

$\lambda_{\max }=$ Autovalor Máximo (Saaty, 1987).

Contudo, para validar os valores ou escalas de prioridades, é calculada a razão da consistência, que será obtida pela seguinte divisão:

$$
R C=\frac{I C}{I R}
$$

Em que, $I C$ = Índice de consistência e $I R$ = índice Randômico (Saaty, 1987)

Conforme esta escala calculada por Saaty (1987), o índice RC é aceitável a uma razão menor ou igual a 0,10 . O número do IR é obtido da escala de ordem de matriz (n), elaborada pelo próprio Saaty.

\subsection{Trabalhos em AHP}

Muitos são os trabalhos publicados referentes à aplicação do AHP nos mais variados campos. Ho, Dey, e Higson (2006) após realizar pesquisa de revisão de literatura sobre o AHP, evidenciou que várias ferramentas podem ser combinadas com este método, dentre as quais a programação matemática, a análise SWOT (Strengths, Weaknesses, Opportunities, Threats) e a análise envoltória de dados (DEA). O autor analisou 66 artigos relacionados que aparecem nas revistas internacionais no período1997-2006. Dos artigos analisados, 33 trabalhos (50\%) representavam integração entre o AHP com a programação matemática, apresentando técnicas combinadas com programação linear (isolada ou mista) e programação de metas; e 5 trabalhos (7,6\%) incorporavam o AHP integrado à análise SWOT.

Granemann e Gartner (1998) utilizaram o AHP para a escolha da melhor forma de financiamento de aeronaves, justificando, que para este setor, a forma de financiamento exerce expressiva influência na estrutura de capital dessas empresas. Diferentes variáveis devem ser ponderadas para a melhor escolha, apresentando, assim, campo fértil para a aplicação do AHP, sendo que as opções de financiamento estudadas eram: leasing financeiro, leasing operacional e empréstimo bancário.

Amaral, Silva e Teixeira (2007) abordaram a aplicação do Sistema de Apoio à Decisão (SAD), utilizando a Análise Hierárquica como ferramenta de auxílio ao pequeno e médio produtor rural da região de Betim (MG), em atividades de planejamento da produção bovina de corte. A pesquisa foi realizada em duas fases, sendo que na primeira buscou-se classificar os seguintes objetivos: maximização da margem bruta, minimização do risco e a maximização da comercialização.Na segunda fase, o foco foi na classificação dos fatores importantes de cada fase da produção bovina de corte. A conclusão foi que, para o produtor rural da região de Betim (MG), a atividade de recria é a que oferece as melhores condições de se obter maior margem bruta, menor risco e boas condições comerciais, principalmente no município de Betim (MG), onde é muito pequena a produção agropecuária e as terras têm alto custo de oportunidade. 


\section{Procedimentos Metodológicos}

Este artigo se apoia no método indutivo, apresentando uma abordagem empírica de cunho quantitativo. Conforme Demo (1995, p. 136), a indução "parte do particular e coloca a generalização como produto posterior do esforço de coleta de casos particulares". Quanto a seus objetivos, esta pesquisa adotou um delineamento exploratório-descritivo, em função de apresentar uma nova abordagem sobre um tema e de ampliar seus estudos, enquadrando-se na tipologia apontada por Martins (2007).

Quanto aos procedimentos de pesquisa, foi utilizada a entrevista semiestruturada. Estas entrevistas foram realizadas com peritos-contadores credenciados na Associação dos Peritos Judiciais, Árbitros, Conciliadores e Mediadores de Minas Gerais (Aspejudi - MG). Optou-se pela escolha dos peritos-contadores registrados nesta associação profissional para melhor focar na população-base para a amostra, posto que nem todos os contadores registrados no Conselho Regional de Contabilidade de Minas Gerais realizam perícias contábeis, como também nem todos os peritos-contadores realizam perícias de apuração de haveres. Nesse sentido, realizou-se pesquisa no site da Aspejudi-MG, evidenciando 17 peritos especialistas em apuração de haveres e 6 que informaram especialidade em avaliação de sociedades, sendo que 3 aparecem em ambos os grupos. Dessa forma, foi levantado um total de 20 peritos contadores cadastrados na Aspejudi-MG que informaram ter entre suas especialidades a avaliação de sociedades e/ou apuração de haveres. Desses, foram entrevistados 8, correspondendo a 40\% do total. Conforme Rosa e Arnoldi (2008), foi elaborado um protocolo de entrevista, que visa à construção de um roteiro e de uma estruturação para a coleta de dados.

Os peritos-contadores respondentes se caracterizam por serem profissionais atuantes no mercado, com formação em Ciências Contábeis, sendo que, dos oito respondentes, quatro obtiveram outra titulação, variando entre Administração, Economia e Direito. Cinco profissionais atuam no ramo pericial há mais de 20 anos, enquanto dois profissionais atuam há mais de 14 anos e um profissional contava com sete anos de atuação durante o período de entrevistas. Todos os profissionais têm pelo menos uma pós-graduação lato sensu, com ênfase variando entre Controladoria, Auditoria e Finanças, e três profissionais possuem pós-graduação stricto sensu, mestres em Ciências Contábeis. Quanto ao gênero, sete profissionais são do sexo masculino e uma do sexo feminino.

Apesar de o levantamento dos dados ter sido por meio de entrevistas, neste artigo, especificamente, o foco é a evidenciação dos principais aspectos e prioridades para os peritos- contadores, quanto à avaliação de sociedades em perícias de apuração de haveres, utilizando-se o Método de Análise Hierárquica (AHP), que se configura como um procedimento eminentemente quantitativo. Não obstante, ressalta-se que para o uso do método AHP, como modelo matricial para a tomada de decisão, são pertinentes amostras pequenas, conforme metodologia a ser detalhada.Assim, as entrevistas foram estruturadas de forma a buscar conhecer a formação do profissional, o tempo de atuação, a quantidade de trabalhos já realizados, a forma de planejamento, a abordagem quanto aos intangíveis, seus valores e escolhas quanto aos métodos de avaliação.Buscou-se ainda investigar sobre o ponto de vista e a consequente escolha do método de avaliação em função de aspectos contábeis, como, por exemplo a continuidade da empresa, a qualidade da escrituração contábil, as receitas, a rentabilidade e a lucratividade, assim como o imobilizado.

Nesse contexto, objetivou-se apurar qual método de avaliação apresenta melhor julgamento dado pelos peritos-contadores, tendo toda essa estrutura alicerçada na formação acadêmica, experiência profissional, percepção quanto aos atributos de intangibilidade, receita, lucratividade, entre outros aspectos capazes de trazer ao pesquisador, conforme propõe o método AHP, condições de quantificar aspectos preferenciais dos julgadores, considerando os diversos critérios e alternativas de escolha, dando assim uma hierarquia de valores quanto ao que se pretende avaliar.

Não obstante, ressalta-se a limitação do método AHP para o trabalho em pequenas amostras, pois o aspecto geográfico de atuação da Aspejudi-MG, é limitado aos peritos-contadores atuantes no Estado de Minas Gerais, não podendo assim ocorrer generalizações em termos de nação, seja pelo prisma da população, seja pelo tamanho da amostra. 


\section{Análise Quantitativa: Aplicação do Ahp}

\subsection{Determinação da Estrutura Hierárquica}

Seguindo a estrutura proposta por Lyra (2008) para a construção da análise hierárquica, foi definida a estrutura hierárquica e os parâmetros de comparação a serem utilizados, conforme modelo representado na Figura 3.

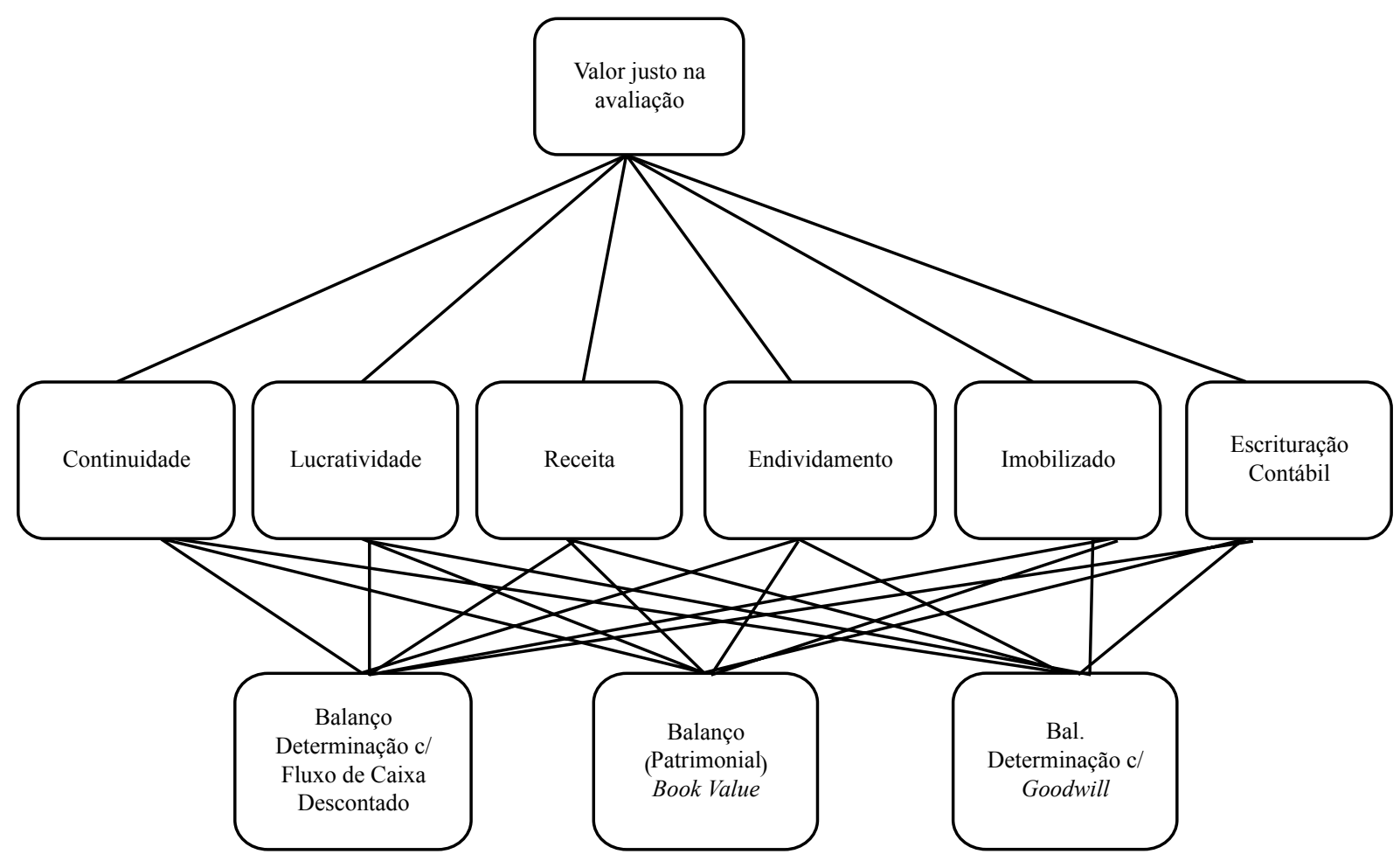

Figura 3. Estrutura hierárquica de problemas de decisão do Método de Avaliação em apuração de haveres

Fonte: elaborado pelos autores.

A partir desta estrutura hierárquica, são definidos:

- Meta/objetivo = valor justo na avaliação: apresenta o objetivo geral do que se pretende com a análise hierárquica. Para os fins desta pesquisa, entende-se que o objetivo da utilização das alternativas (diversos métodos de avaliação) decorre de critérios que serão determinantes. Os peritos-contadores têm como meta a avaliação da entidade pelo seu valor justo, considerando todas estas variáveis.

- Critérios = (Continuidade, Lucratividade, Receita, Endividamento, Imobilizado e Escrituração Contábil): são os principais fatores que determinarão as escolhas das alternativas. Estes critérios poderiam ainda ser desmembrados em subcritérios.

Especificamente para a análise hierárquica desta pesquisa, os critérios escolhidos são:

- Continuidade: além de constituir-se em um postulado a ser obedecido no levantamento das demonstrações contábeis (CPC, 2011), é um fator preponderante na avaliação de sociedades. Neste aspecto, a avaliação do empreendimento tem por viés perspectivas futuras de caixa como determinante para a escolha do modelo de avaliação e apuração do goodwill (Assaf Neto, 2006; Damodaram, 2005; Iudícibus, 2000). 
- Lucratividade: Laro e Pratt (2005) consideram a Lucratividade um diferencial na avaliação de sociedades, principalmente se confrontar as avaliações que utilizam os múltiplos de faturamento, como uma proxy, para comparar avaliações feitas por outras metodologias.

- Receita: conforme Martins et al.(2001, p.271), é utilizada em avaliações de empresas que não possuem uma escrita contábil ou, se possuem, nela não se pode confiar. Uma opção, apesar de não ser a mais científica (Tiburcio Silva, 2008), é a avaliação por múltiplos, ou relativa. Como fator de determinação de valor da empresa neste método encontra-se a receita ou faturamento da empresa.

- Endividamento: conforme Laro e Pratt (2005), em abordagens baseadas na avaliação de ativos, são também examinados passivos da empresa que não estão propriamente evidenciados, por exemplo, passivos contingentes e contratos de leasing.

- Imobilizado: se, de um lado, tem-se a continuidade como premissa para a escolha do método de avaliação, Iudícibus (2000) destaca que em entidades em processo de descontinuidade, seus ativos devem ser avaliados pelo valor de liquidação. Depreende-se que, nessa circunstância, o inventário dos ativos, contrapondo-se ao levantamento dos passivos, constituirá procedimento pertinente para a avaliação da empresa.

- Escrituração contábil: Montandon (2006) considera que, dentre os obstáculos para a avaliação de micro e pequenas empresas em processos judiciais está a falta de escrituração contábil. Esta consideração também foi confirmada com Paulo et al. (2006), os quais evidenciaram que uma das grandes dificuldades dos peritos-contadores em perícias de apuração de haveres é a falta de escrituração contábil.

- Alternativas = Balanço de Determinação com Fluxo de Caixa Descontado, Balanço Patrimonial (book value) e Balanço de Determinação com Goodwill: serão as alternativas que deverão ser escolhidas de acordo com os critérios. Especificamente nesta pesquisa, estas alternativas representam a conjugação do Balanço de Determinação com os métodos de avaliação a serem empregados: Fluxo de Caixa Descontado, valor contábil e goodwill (fórmulas específicas de cálculo).

Aclara-se que mesmo no Balanço de Determinação com Fluxo de Caixa Descontado pode ser apurado o goodwill, pela diferença entre o valor apurado pelo fluxo de caixa menos o valor de todos os ativos a valor de mercado. Todavia, a alternativa Balanço de Determinação com Goodwill representa os ativos avaliados a valor de mercado mais o goodwill calculado por meio de métodos específicos.

\subsection{Análise dos Resultados}

Para a aplicação do AHP, foi utilizado o software livre Open Decision Maker na versão 1.0.1, licenciado por GPL (General Public License), disponível em http://sourceforge.net/projects/opendecisionmak/. Este programa apura a Prioridade Global (PG) representada pela apuração do ranking das alternativas. Calcula a Prioridade Média Local (PML) em relação aos critérios julgados entre si, de forma geral, representados no software pela matriz alternative- main criterion - matrix. Apura ainda a prioridade dos critérios, apresentando também a hierarquia destes.

\subsubsection{Matrizes de Relação de Preferência e Apuração da Prioridade Global}

Tendo sido definido o objetivo, os critérios e as alternativas (métodos de avaliação de sociedades em processos judiciais de apuração de haveres) foram realizadas as entrevistas com os peritos-contadores com o intuito de montar as matrizes de preferências destes peritos por meio da escala de julgamentos. As comparações foram feitas par a par, em forma linear, conforme determina o AHP. Destaca-se que a escala de julgamento tem variação de 1 a 9 . 
O primeiro passo foi a elaboração da matriz de desempenho das alternativas: Avaliação pelo Balanço de Determinação com Fluxo de Caixa Descontado (ABDFC), Avaliação pelo Book Value (ABV) e Avaliação pelo Balanço de Determinação com Goodwill (ABDG), com base em cada critério. Os critérios escolhidos foram: Continuidade (CC), Lucratividade (CL), Receita (CR), Endividamento (CE), Imobilizado (CI) e Escrituração Contábil (CES).

Foram elaboradas 8 matrizes de importância dos critérios, correspondentes a cada perito-contador entrevistado. Após a construção destas matrizes, foi calculada a média aritmética das prioridades apontadas pelos peritos-contadores e apurada a matriz de comparação normalizada referente à média calculada. A seguir, apresenta-se a matriz elaborada por meio desse procedimento conforme Tabela 1.

Tabela 1

Matriz de importância dos critérios

\begin{tabular}{ccccccc}
\hline Critérios & CC & CL & CR & CE & CI & CES \\
\hline $\mathrm{CC}$ & $\mathbf{1 , 0}$ & 5,0 & 5,0 & 6,0 & 5,0 & 2,0 \\
\hline $\mathrm{CL}$ & $1 / 5$ & $\mathbf{1 , 0}$ & 2,0 & 1,0 & 3,0 & 2,0 \\
\hline $\mathrm{CR}$ & $1 / 5$ & $1 / 2$ & $\mathbf{1 , 0}$ & 1,0 & 2,0 & 2,0 \\
\hline $\mathrm{CE}$ & $1 / 6$ & 1,0 & 1,0 & $\mathbf{1 , 0}$ & 2,0 & 2,0 \\
\hline $\mathrm{Cl}$ & $1 / 5$ & $1 / 3$ & $1 / 2$ & $1 / 2$ & $\mathbf{1 , 0}$ & 2,0 \\
\hline $\mathrm{CES}$ & $1 / 2$ & $1 / 2$ & $1 / 2$ & $1 / 2$ & $1 / 2$ & $\mathbf{1 , 0}$ \\
\hline
\end{tabular}

Fonte: dados da pesquisa.

Conforme a Tabela 1, são lançados os julgamentos paritários dos critérios entre si, sendo que na diagonal principal apura-se uma prioridade igual a 1, pois uma variável comparada a ela mesma terá o mesmo nível de prioridade, abaixo da diagonal principal, os elementos serão uma função recíproca dos elementos acima desta diagonal, de forma que sendo $a_{i j}>0, a_{j i}$ será $=1 / a_{i j}$ Para entendimento dessa matriz de importância, pode-se analisar o critério Continuidade (CC) que comparado aos critérios Lucratividade (CL), Receita (CR) e Imobilizado (CI) apresenta um peso 5 , enquanto que no critério qualidade da Escrituração Contábil (CES) o peso foi somente 2. Tais números apontam que a Continuidade tem importância forte ou essencial sobre Lucratividade, Receita, Imobilizado e importância moderada em relação à qualidade da Escrituração Contábil.

Após a construção da matriz de prioridade dos critérios, foi feita a sua normalização, sendo apurado o seguinte vetor das Prioridades Médias Locais (PML).

Tabela 2

Prioridade Média Local apurada

\begin{tabular}{lc}
\hline Continuidade & $46,13 \%$ \\
\hline Lucratividade & $16,54 \%$ \\
\hline Receita & $10,83 \%$ \\
\hline Endividamento & $10,60 \%$ \\
\hline Escrituração Contábil & $8,29 \%$ \\
\hline Imobilizado & $7,61 \%$ \\
\hline Fonte: dados da pesquisa.
\end{tabular}

Conforme a Tabela 2, as prioridades médias locais apuradas indicam que para os peritos-contadores o principal critério, dentre os apresentados para a elaboração das matrizes de prioridades, foi o de Continuidade, que obteve o percentual de 46,13\%. Tais preferências reforçam as contribuições de Iudícibus (2000), Martins et al. (2001), Damodaram (2005) e Assaf Neto (2006), quando estabelecem a Continuidade no empreendimento como pressuposto para a avaliação dos ativos com base nas perspectivas de benefícios futuros 
ou no valor de liquidação desses ativos no caso de encerramento ou inviabilidade do negócio. Em seguida, aparecem os critérios Lucratividade, Receita e Endividamento, que apresentam percentual inferior a 20\%, e os critérios Escrituração Contábil e Imobilizado, que apresentaram percentual inferior a 10\%. Nota-se que para os profissionais entrevistados aspectos como lucratividade da sociedade e receita receberam um peso maior que a qualidade da escrituração contábil. Tal evidenciação denota que mesmo em processos judiciais aspectos como capacidade da sociedade em gerar valor para os sócios e capacidade de gerar entradas de recursos derivados do objeto social do empreendimento receberam maior peso do que a qualidade da escrituração contábil.

O critério Imobilizado, apesar de ser considerado relevante quando da avaliação de entidades utilizando a abordagem de cálculo do goodwill por meio de fórmulas específicas, como também nas avaliações pelo valor de liquidação dos ativos, recebeu menor prioridade, apresentando um percentual de 7,61\%.

O passo seguinte consistiu na elaboração das matrizes de preferência em relação a cada critério. As Tabelas 3 a 5 apresentam as matrizes de importância dos critérios escolhidos em relação às alternativas Avaliação pelo Balanço de Determinação com Fluxo de Caixa Descontado (ABDFC), Avaliação pelo Book Value (ABV), e Avaliação pelo Balanço de Determinação com Goodwill (ABDG).

Tabela 3

Matrizes de importância dos critérios Continuidade e Lucratividade

\begin{tabular}{cccc|cccc}
\hline \multicolumn{4}{c}{ Critério Continuidade } & \multicolumn{4}{c}{ Critério Lucratividade } \\
\hline CC & ABDFC & ABV & ABDG & CL & ABDFC & ABV & ABDG \\
\hline ABDFC & 1,00 & 8,0 & 4,0 & ABDFC & 1,0 & 7,0 & 3,0 \\
\hline ABV & $1 / 8$ & 1,0 & $1 / 5$ & ABV & $1 / 7$ & 1,0 & $1 / 6$ \\
\hline ABDG & $1 / 4$ & 5,0 & 1,0 & ABDG & $1 / 3$ & 6,0 & 1,0 \\
\hline
\end{tabular}

Fonte: dados da pesquisa.

Tabela 4

Matrizes de importância dos critérios Receita e Endividamento

\begin{tabular}{cccc|cccc}
\hline \multicolumn{4}{c}{ Critério Receita } & \multicolumn{4}{c}{ Critério Endividamento } \\
\hline CR & ABDFC & ABV & ABDG & CE & ABDFC & ABV & ABDG \\
\hline ABDFC & 1,0 & 5,00 & 2,0 & ABDFC & 1,0 & 4,00 & 2,0 \\
\hline ABV & $1 / 5$ & 1,0 & $1 / 6$ & ABV & $1 / 4$ & 1,0 & $1 / 3$ \\
\hline ABDG & $1 / 2$ & 6,0 & 1,0 & ABDG & $1 / 2$ & 3,0 & 1,0 \\
\hline
\end{tabular}

Fonte: dados da pesquisa.

Tabela 5

Matrizes de importância dos critérios Imobilizado e Escrituração Contábil

\begin{tabular}{cccc|cccc}
\hline & \multicolumn{4}{c}{ Critério Escrituração Contábil } \\
\hline $\mathrm{Cl}$ & ABDFC & ABV & ABDG & CES & ABDFC & ABV & ABDG \\
\hline ABDFC & 1,00 & 4,0 & 2,0 & ABDFC & 1,00 & 4,0 & 1,0 \\
\hline ABV & $1 / 4$ & 1,0 & $1 / 4$ & ABV & $1 / 4$ & 1,0 & $1 / 3$ \\
\hline ABDG & $1 / 2$ & 4,0 & 1,0 & ABDG & 1,00 & 3,0 & 1,0 \\
\hline
\end{tabular}

Fonte: dados da pesquisa.

A Tabela 6 apresenta as prioridades médias locais apuradas conforme determina o AHP. No critério Continuidade, a alternativa que alcançou maior pontuação foi Avaliação pelo Balanço de Determinação com Fluxo de Caixa Descontado (ABDFC), obtendo 69,87\% de importância, seguida pela Avaliação pelo Balanço de Determinação com Goodwill (ABDG), com 23,70\%, e a Avaliação pelo Book Value (ABV), com 
6,43\%. A alternativa Avaliação pelo Balanço de Determinação com Fluxo de Caixa Descontado (ABDFC) também recebeu o maior grau de importância entre os demais critérios: Lucratividade $(64,06 \%)$, Receita (54,98\%), Endividamento (55,84\%), Imobilizado (54,69\%) e Escrituração Contábil (45,79\%). Na segunda colocação por grau de importância, conforme a escala de julgamento dos peritos e procedimentos de cálculo do AHP, ficou a alternativa Avaliação pelo Balanço de Determinação com Goodwill (ABDG).

Tabela 6

Prioridades Médias Locais (PMLs) critérios e alternativas

\begin{tabular}{lcccccc} 
& CC & CL & CR & CE & Cl & CES \\
\hline ABFCD & $69,87 \%$ & $64,06 \%$ & $54,98 \%$ & $55,84 \%$ & $54,69 \%$ & $45,79 \%$ \\
\hline ABV & $6,43 \%$ & $6,68 \%$ & $8,21 \%$ & $12,20 \%$ & $10,86 \%$ & $12,60 \%$ \\
\hline ABDG & $23,70 \%$ & $29,26 \%$ & $36,81 \%$ & $31,96 \%$ & $34,45 \%$ & $41,61 \%$ \\
\hline
\end{tabular}

Fonte: dados da pesquisa.

Conforme se pode evidenciar no Figura 4, a alternativa Avaliação pelo Balanço de Determinação com Fluxo de Caixa Descontado (ABDFC), tendo por base os critérios Continuidade, Lucratividade, Receita, Endividamento, Imobilizado e Escrituração Contábil, foi a que recebeu maior peso e importância em todos os julgamentos.

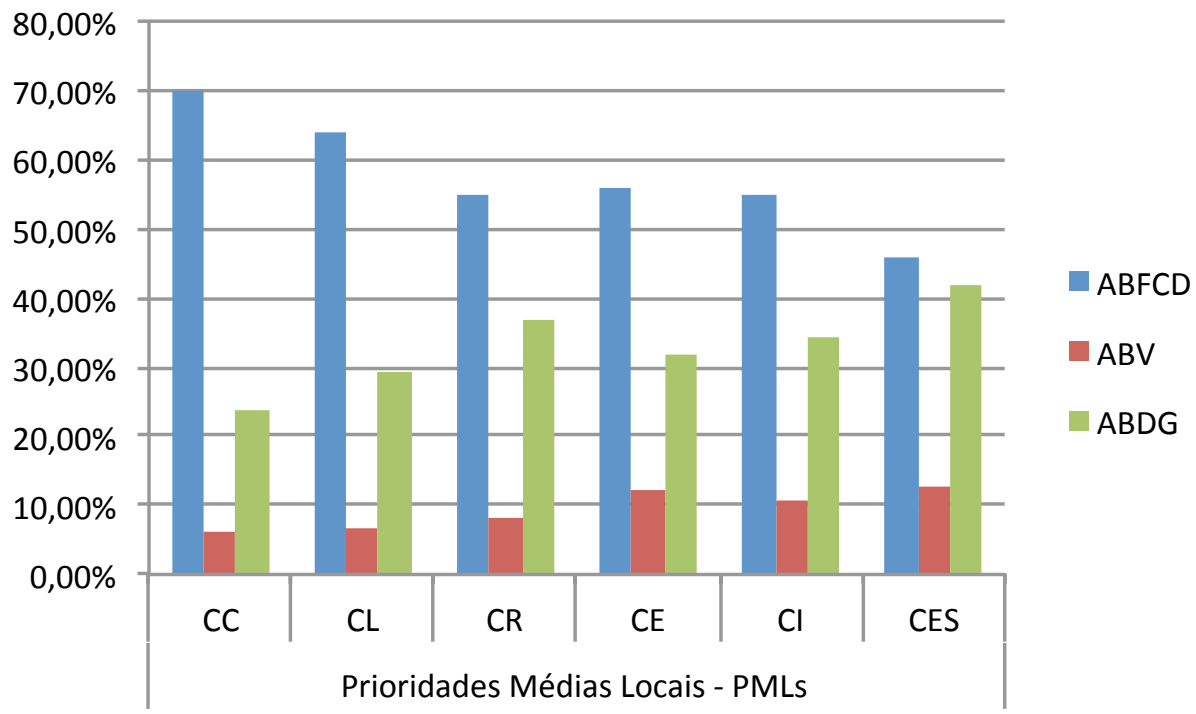

Figura 4. Prioridades Médias Locais dos critérios em relação às alternativas Fonte: dados da pesquisa.

O software Open Decision Maker também efetua os cálculos da Razão de Consistência, conforme apontado por Saaty quando moldou o AHP. Este algoritmo, conforme Saaty (1987), tem por objetivo evidenciar a consistência das matrizes elaboradas e sua validade. Assim, para a validação dos vetores de preferência apurados, as Razões de Consistência (RC) devem estar no patamar de até 0,10 . As Razões de Consistência apuradas nas matrizes de cada critério foram: 
Tabela 7

Razões de Consistência

\begin{tabular}{ll}
\hline \multicolumn{1}{c}{ Critérios } & RC \\
\hline Continuidade & 0,08 \\
\hline Lucratividade & 0,09 \\
\hline Receita & 0,07 \\
\hline Endividamento & 0,02 \\
\hline Escrit. Contábil & 0,01 \\
\hline Imobilizado & 0,05 \\
\hline Fonte: dados da pesquisa. &
\end{tabular}

\subsubsection{Apuração da Prioridade Global}

A etapa final constitui-se na apuração da Prioridade Global (PG), que, conforme Costa (2002), representa o vetor que tem armazenado a prioridade de cada alternativa em relação ao foco principal, ou ao objetivo geral. Os elementos da PG expressam os desempenhos das alternativas à luz do objetivo geral ou foco principal. Dessa forma, são agregados os vetores das Prioridades Médias Locais (PMLs) apuradas para cada critério ao vetor do Objetivo Geral (OG) (Santos, 2008).

Tabela 8

Apuração da Prioridade Global (PG)

\begin{tabular}{cc}
\hline Alternativa & PG \\
\hline ABFCD & $62,66 \%$ \\
\hline ABV & $8,12 \%$ \\
\hline ABDG & $29,22 \%$ \\
\hline
\end{tabular}

Fonte: dados da pesquisa.

Conforme mostra a Tabela 8 e o Figura 5, a alternativa que apresentou os maiores atributos, de acordo com a hierarquia das prioridades determinadas pelos peritos-contadores entrevistados foi Avaliação pelo Balanço de Determinação com Fluxo de Caixa (ABFCD) (Prioridade Global = 0,6266).

\section{Prioridade Global PG}

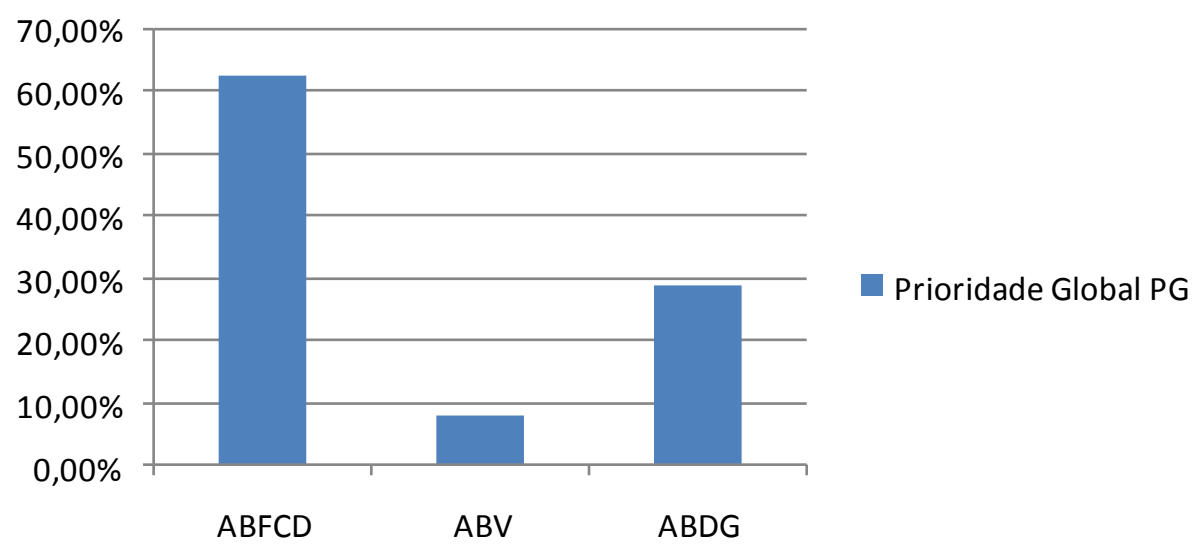

Figura 5 . Prioridade Global 


\section{Considerações Finais}

O objetivo geral deste artigo consistiu em identificar, por meio da aplicação do AHP, as preferências dos peritos-contadores quanto ao emprego de diferentes métodos e/ou procedimentos de avaliação de sociedades aplicados em processos judiciais de apuração de haveres.

Foram abordados os métodos de avaliação de sociedades e explanou-se sobre o Balanço de Determinação como ferramenta para a apuração dos haveres, do sócio falecido ou excluído, incorporando o goodwill, quando evidenciado, como também os ativos a valor de mercado e os passivos a valor presente.

Muito embora as preferências dos peritos-contadores pudessem ser apuradas somente pelas entrevistas, o mérito da utilização do AHP deriva da possibilidade de quantificação dos critérios utilizados para a avaliação das sociedades em processos judiciais, permitindo, assim, uma mensuração do grau dessas preferências. Tal procedimento confere uma forma de medida mais objetiva e positivista.

O uso do AHP evidenciou que critérios como Receita, Imobilizado e Endividamento, para a quase totalidade dos peritos-contadores entrevistados, não são determinantes para a escolha do método de avaliação de sociedades a ser empregado em perícias de apuração de haveres, assim como também como a qualidade da Escrituração Contábil. Conforme as prioridades médias apuradas, estes critérios obtiveram os seguintes percentuais: Receita, 10,83\%; Endividamento, 10,60\%; Escrituração Contábil, 8,29\%; e Imobilizado, 7,61\%. Todavia, há de se ressaltar que, quando analisadas as percepções dos peritos-contadores quanto à Escrituração Contábil, por meio das entrevistas realizadas, este critério recebeu aprovação de 5 peritos, considerando que pode ser um determinante para a escolha do método de avaliação de sociedades a ser empregado em perícias de apuração de haveres.

Lado outro, com base nas Prioridades Médias Locais apuradas, constatou-se que para os peritos-contadores o principal critério, dentre os apresentados para a elaboração das matrizes de prioridades, foi a Continuidade, com 46,13\%. Lucratividade, Receita e Endividamento apresentaram percentual inferior a 20\% e Escrituração Contábil e Imobilizado apresentaram percentual inferior a 10\%. Infere-se que para os profissionais entrevistados a lucratividade e a receita foram mais prioritárias do que a qualidade da escrituração contábil. Tal evidenciação leva a concluir que, para os peritos-contadores, a capacidade da sociedade em gerar valor para os sócios e gerar entradas de recursos receberam maior peso do que a qualidade da Escrituração Contábil, apesar de a maioria dos peritos-contadores concordarem sobre a importância da escrituração contábil para as apurações de haveres. Essa constatação pode ser considerada pertinente, levando-se em conta o fato que em trabalhos periciais de apuração de haveres é muito comum o problema de assimetria informacional.

Destacam-se, ainda, limitações apontadas por Ornelas (2010), amparado em jurisprudência sobre o tema, argumentando que eventos patrimoniais futuros não afetam a apuração de haveres, defendendo que o Fluxo de Caixa Descontado seria impertinente para perícias de apuração de haveres e que este método não evidencia o excesso de lucros ou super-lucros, que são a base para o cálculo do goodwill.

Todavia, a utilização do AHP, com base nos critérios apresentados e nas alternativas propostas, apontou como preferência dos peritos-contadores entrevistados, como método que recebeu a maior prioridade, a alternativa Avaliação pelo Balanço de Determinação com Fluxo de Caixa Descontado (ABFCD), que apresentou a prioridade global (PG) com 62,66\%. O Balanço de Determinação com Goodwill (ABDG) apurou $29,22 \%$ e a Avaliação pelo Book Value (ABV), 8,12\%.

Dessa forma, pode-se considerar a utilidade do AHP como ferramenta para a apuração da melhor alternativa quanto aos métodos de avaliação de sociedades em perícias judiciais de apuração de haveres, como também para a quantificação do grau de importância dos critérios utilizados para a escolha desses métodos. 
Como limitações da pesquisa destacam-se a característica de a população estar estabelecida geograficamente em um único estado, limitando, assim, a generalização dos resultados encontrados e o caráter subjetivo do AHP, não do método em si, mas, sim, dos julgamentos subjetivos de cada entrevistado para a montagem da matriz de prioridades e, assim, posteriormente, apurar as Prioridades Locais Médias e a Prioridade Global. Também se pode apontar como limitação para a melhor utilização do AHP a não elaboração de uma análise de sensibilidade dos dados pelo software utilizado para a construção das matrizes e a aplicação do método de análise hierárquica.

Para pesquisas futuras, sugere-se a análise sobre novos acórdãos quanto à jurisprudência em apuração de haveres, seja no Superior Tribunal de Justiça ou, até mesmo, nos tribunais estaduais, no que se refere aos métodos de avaliação de sociedades empregados, principalmente no que se refere à utilização do fluxo de caixa descontado.

\section{Referências}

Alberto, Valder Luis Palombo. (2000). Perícia contábil. 2a ed. São Paulo: Ed. Atlas.

Amaral, Juliano F. S.; SILVA, Jersone. T. M. \&TEIXEIRA, Luiz Antônio A. (2007). Aplicação do processo analítico hierárquico como suporte à decisão na produção bovina de corte na região de Betim/MG. Contabilidade Vista \& Revista, 18(3), pp. 133-159.

Assaf Neto, Alexandre. (2006). Finanças corporativas e valor. São Paulo: Atlas.

Brasil. Código de processo civil. Lei no 5.869 de 11 de janeiro de 1973. (2010). VadeMecum: acadêmico de direito/Anne Joyce Angher (Org.). 10ª ed. São Paulo: Rideel.

Comitê de Pronunciamentos Contábeis. Cpc 00 R1: Estrutura Conceitual para Elaboração e Divulgação de Relatório Contábil-Financeiro. Brasília, 2011. Recuperado em 05 de junho, 2013. Disponível em: $<$ http://static.cpc.mediagroup.com.br/Documentos/147_CPC00_R1.pdf >.

Costa, Helder G. (2002). Introdução ao método de análise hierárquica:análise multicritério no auxílio à decisão. Niterói, RJ: H. G. Costa, 2002. Recuperado em 21 de julho, 2013. Disponível em:<http:// www.din.uem.br/sbpo/sbpo2004/pdf/arq0279.pdf >.

Damodaran, Aswhat. (1997). Avaliação de investimentos:ferramentas e técnicas para determinação do valor de qualquer ativo. Rio de Janeiro: Qualitymark Editora.

Damodaran, Aswhat. (2005). Valuation approaches and metrics: a survey of the theory and evidence. Foundations \& Trends In Finance1, n. 8, pp. 693-784. http://dx.doi.org/10.1561/0500000013

Oliveira, Andre L. S. de. O princípio da preservação da empresa manifestado no Código Civil sob uma perspectiva societária. (2011). Revista Eletrônica de Direito da Universidade Castelo Branco. Recuperado em 16 de julho, 2013. Disponível em:<ww.castelobranco.br/sistema/novoenfoque/files/04/ revista_eletronica_de_direito_da_ucb_principio_da_preservacao_da_empresa_manifestado_no_ codigo_civil_sob_uma_perspectiva_societaria.pdf $>$.

Demo, Pedro. (1995). Metodologia científica em ciências sociais. $3^{a}$ ed. São Paulo: Atlas.

Fernández, Pablo. (2007). Company valuation methods. The most common errors in valuation. Working Paper. 25p. Madrid. IESE Business School, 2002.

Granemann, Sergio R. \& Gartner, Ivan R. (1198). Seleção de financiamento para aquisição de aeronaves: uma aplicação do método de análise hierárquica (AHP). Transportes, v. 6, n.1. doi: 10.14295/transportes.v6i1.238 
Gomes, L. F. A. M.; Araya, M. C. G.\& Carignano, C. (2004). Tomada de decisões em cenários complexos: introdução aos métodos discretos do apoio multicritério à decisão. São Paulo: Pioneira Thomson Learning.

Hitchner, James. (2003). Financial valuation: applications and models. New Jersey: John Wiley \& Sons.

Ho, W.; Dey, P.k. \& Higson, H.e. (2006). Multiple criteria decision making techniques in higher education. International Journal of Educational Management, 20(5), pp. 319-337. doi:10.1108/09513540610676403

Hoog, Wilson Z. (2010). Resolução de sociedade \& Avaliação do patrimônio na apuração de haveres. Curitiba: Juruá.

Ishizaka A.\& Labib A. (2011). Review of the main developments in the analytic hierarchy process. Expert Systems with Applications, 38(11), pp.14336-14345.doi: 10.1016/j.eswa.2011.04.143

Iudícibus, Sérgio de. (2000). Teoria da contabilidade. 6ª ed. São Paulo: Atlas.

Kroenke, Adriana \& HEIN, Nelson. (2011). Avaliação de empresas por meio de indicadores de atividade: uma aplicação do método AHP. REGE, São Paulo - SP, Brasil, 18(4), p. 605-620.

Laro, David \& Pratt, Shannon P. (2005). Business valuation and taxes: procedure, law, and perspective. New Jersey: John Wiley \& Sons.

Lyra, Ricardo L. W. C. de. (2008). Análise hierárquica dos indicadores contábeis sob óptica do desempenho empresarial. Tese de Doutorado. Universidade de São Paulo, São Paulo, SP, Brasil.

Martelanc, Roy; PASIN, Rodrigo \& Pereira, Fernando. (2010). Avaliação de empresas: um guia para fusões \& aquisições e private equity. São Paulo: Pearson Prentice Hall.

Martins, Elizeu et al. (Org.). (2001). Avaliação de empresas: da mensuração contábil à econômica - FIPECAFI. São Paulo: Atlas.

Martins, Gilberto de Andrade. (2007). Manual para elaboração de monografias e dissertações. $3^{a}$ ed. São Paulo: Atlas.

Montandon, Tabele M. (2006). Avaliação de empresas em perícias judiciais contábeis: um estudo de casos. Dissertação de Mestrado em Ciências Contábeis, Faculdade de Administração e Ciências Contábeis, Universidade Federal do Rio de Janeiro, Rio de Janeiro, RJ, Brasil.

Oliveira, Andre L. S. de. O princípio da preservação da empresa manifestado no Código Civil sob uma perspectiva societária. (2011). Revista Eletrônica de Direito da Universidade Castelo Branco. Recuperado em 16 de julho, 2013. Disponível em:<ww.castelobranco.br/sistema/novoenfoque/files/04/ revista_eletronica_de_direito_da_ucb_principio_da_preservacao_da_empresa_manifestado_no_ codigo_civil_sob_uma_perspectiva_societaria.pdf>.

Ornelas, Martinho M. G. de. (2000a). Contribuição à formulação de um sistema conceitual contábil de apuração de haveres em processos judiciais. Tese de Doutorado, Universidade de São Paulo, São Paulo, SP, Brasil.

Ornelas, Martinho M. G. de. (2000b). Perícia contábil. 3ª ed. São Paulo: Ed. Atlas.

Ornelas, Martinho M. G. de. (2003), Avaliação de sociedades: apuração de haveres em processo judiciais. $2^{\text {a }}$ ed. São Paulo: Atlas.

Ornelas, Martinho M. G. de. (2010); A impropriedade da adoção do fluxo de caixa descontado em procedimento judicial de apuração de haveres. Recuperado em 14 de maio, 2014. Disponível em: <http:// www.contadoresforenses.net.br/trabalhos.php>. 
Paulo, Edilson; Cunha, Jacqueline V. A. da; Alencar, Roberta C \& Martins, Eliseu. de. (2006). As práticas dos peritos contadores na apuração de haveres. RBGN - Revista Brasileira de Gestão de Negócios. São Paulo, 8(22), pp. 23-36.

Peleias, Ivam R.; Nogueira, Marcelo Francisco; PARISI, Cláudio \& Ornelas, Martinho Maurício Gomes de. (2009). Otimização do mix operacional de um escritório de perícias: uma aplicação de programação linear. Revista Contabilidade Vistaß Revista, 19(1), pp. 37-60.

Perez, Marcelo M. \& FAMÁ, Rubens. (2004). Métodos de avaliação de empresas e o balanço de determinação. Administração em Diálogo, São Paulo, n.6, pp. 101-112.

Pires, Marco A. A. (2006). Laudo pericial contábil na decisão judicial. Curitiba: Juruá.

Rosa, M. V. F. P. C \& Arnoldi, M. A. G. C. A entrevista na pesquisa qualitativa: mecanismos para validação dos resultados. Belo Horizonte: Autêntica, 2008.

Saaty, Thomas. (1987).The analytic hierarchy process: what it is and how it is used. Mathematical Modelling, 9(3), pp. 161-176.

Saaty, Thomas. (1991). Método de análise hierárquica. São Paulo: McGraw-Hill.

Saaty, Thomas. (1997). That is not the analytic hierarchy process: what the ahp is and what it is not. Journal of Multi-Criteria Decision Analysis, 6(6), pp. 324, 1997. doi:10.1002/(SICI)1099-1360(199711)6:6<324:AID-MCDA167>3.0.CO;2-Q

Santos, Flávia F. (2008). Análise de investimentos em AMT (Advanced Manufacturing Technology):uso de um modelo multicriterial - AHP (Analytic Hierarchy Process). Dissertação de Mestrado, Universidade Federal de Minas Gerais. Belo Horizonte, MG, Brasil.

Santos, Nivaldo J. dos. (2011). Metodologia para determinação do valor econômico de empresas de capital fechado em processos de apuração de haveres de sócio. Tese de Doutorado, Universidade Federal de Santa Catarina, Centro Tecnológico. Programa de Pós-Graduação em Engenharia de Produção. Florianópolis, SC, Brasil.

Shanklin, S. B.; Hunter, D. R. \& Ehlen, C. R. (2011). A retrospective view of the IFRS' conceptual path and treatment of fair value measurements in financial reporting. Journal of Business \& Economics Research [serial online]. 9(3), p.23.

Tiburcio Silva, César A. (2008). Avaliação de empresas em processos de resolução societária. RUC - Revista Unieuro de Contabilidade, Brasília, 1(1).. 